International Journal of Engineering \& Technology, $7(4.13)(2018) 155-159$
International Journal of Engineering \& Technology
SPC
Website: www.sciencepubco.com/index.php/IJET
Research paper

\title{
Parametric study of varying ribs orientation and sweep angle of un-tapered wing box model
}

\author{
Ying Nee Chan, Mohammad Yazdi Harmin*, Mohd Safuan Othman \\ Department of Aerospace Engineering, Faculty of Engineering, University Putra Malaysia, 43400 Serdang, Selangor, Malaysia \\ *Corresponding author E-mail: myazdi@upm.edu.my
}

\begin{abstract}
A simple un-tapered wing box model was considered to illustrate an aeroelastic tailoring of varying ribs orientation with respect to a range of sweep angles. This approach allows the bending-torsional modes characteristic to be altered hence offering possibility for improvement in aeroelastic performance without having to compromise its overall weight. Two cases of ribs orientation were considered for a range of sweep angles. The first case was by allowing one individual ribs to be orientated at a time and the second case considering all possible combination of ribs orientation. The finding shows that the torsional modes are greatly influenced by the rib orientation while the bending modes are not significantly affected. Therefore, this enable the frequency gap between the flutter modes to be altered; hence resulting into significant impact to aeroelastic performances. It has been found that for all the considered sweep angles, the varying ribs orientation can lead into an improvement of nearly $80-90 \%$ when compared to its corresponding baseline configuration. Therefore, this provides a leverage for an advancement in aeroelastic performance without having to penalize the total weight of the wing structure.
\end{abstract}

Keywords: aeroelastic tailoring; aeroelasticity; flutter; wing design.

\section{Introduction}

Aeroelasticity is the study that is associated with the interaction of aerodynamics, elastic and inertia forces. Its effects are indeed can lead into a significant impact upon the design and flight performance of the aircraft [1]. Hence, the prediction on the aeroelastic instabilities are extremely important in order to ensure the safety envelope of the aircraft design. Driven by a need to improve the overall efficiency of an aircraft, numerous studies have been conducted through an advancement in materials, aerodynamics, structures, and control technologies. Over the past decades, leveraged has been seen in the composite technology which are widely employed in aerospace industry for the improvement of aeroelastic properties due to its attractive property of strength-to-weight ratio property. This solution has been widely used in the current design of aircraft where the current commercial aircraft is made of 50\% composite material [2]. Meanwhile, the efforts for advancement in aerodynamics has been focusing in shape optimization, where the key criteria are to reduce total drags with significant improvement in lift to drag ratio. Numerous studies have also been conducted by using boundary layer control like plasma actuator $[3,4]$ and surface morphing [5] to delay the flow separation. Apart from that, an innovative design concept in morphing technology has gain much interest through the shape-changing ability for acquiring the best possible aerodynamic shape given the flight condition [6,7].

The approach of aeroelastic tailoring on aircraft design has also becoming a possible solution for the improvement of aircraft performance in terms of aircraft weight reduction $[8,9]$, drag reduction [10], flutter speed improvement [11, 12], and gust load alleviation [13]. This approach can be achieved through either or both the active and passive control of the aeroelastic wing system. It is intended that the aeroelastic instabilities can be delayed and influ- enced in a beneficial way without compromising the weight and performance.

A number of researches has been performed in finding optimum fiber orientation on a composite wing box with aeroelastic instability parameters as the maximizing cost function. One of the research works is by Guo et al. (2003) whom have studied on the effect of laminate lay-up of composite wing box with respect to the flutter speed [14]. Meanwhile, Dillinger et al. (2013) investigated the effect of the variable stiffness along wing span by static aeroelastic optimization of top and bottom of wing skin in terms of lamination parameters and laminate thickness [15]. The other study made by Tian et al. (2016) has performed aeroelastic tailoring on a composite forward-swept wing with parametric variables in terms of composite thickness and orientation parameters [16]. From all these studies, it has been concluded that the parametric design of composite wings laminations provides an impact to the bending-torsional coupling characteristic. Consequently, a better aeroelastic performance can be offered, including further reduction in weight.

Nevertheless, for more than a half century, both external and internal configurations of aircraft structure are still relatively similar. The question then arises whether the classical wing box designs characterized by the straight and parallel ribs and spars have arguably been already optimized as far as possible and whether it is still applicable for supporting future aircraft concepts. Through motivation on the successful studies of varying composite stacking sequence, there has also been recent interest in understanding the effect of wing structure arrangement to its aeroelastic performance.

Sizing optimization of wing-box structure using curvilinear spars and ribs has been performed by Locatelli et al. (2011), where designs with preferable criteria that include weight reduction, stress 
distribution, buckling properties and dynamic behaviors are identified [17]. Besides, Jutte et al. (2014) have implemented few aeroelastic tailoring methods which also includes the usage of curvilinear rib and spar with varying orientation, tow steering composite laminates and also material and thickness grading on a CRM wing box [18]. Meanwhile, Francios et al. (2017) have focused on the modification of spars and stringers planform geometry of a simple rectangular wing box model [19]. All in all, these research works have shown significant effect of curvilinear spars and ribs on the improvement of wing performance.

Harmin et al. (2011) have presented the modification of wing ribs and crenellated skin orientation of a metallic wing [20]. Meanwhile, Othman et al. (2016) have adopted similar aeroelastic tailoring technique by varying each of the ribs individually to investigate its impact on natural frequency and flutter performance [21]. Moreover, Chan et al. (2017) have implemented it to a much realistic wing model of the NASA Common Research Model (CRM) [22]. Recently, Francois et al. (2016) have considered the effect of varying wing sweep angle and ribs arrangement on an un-tapered wing in terms of its static and dynamic aeroelastic behaviour [23]. A much recent research is done by Harmin et. al. (2018), which has presented the parametric study on aeroelastic characteristics of a simple rectangular wing model with all possible combinations of varying ribs orientation [24]. Their work has shown that the frequency gap between the flutter modes can be altered through the varying ribs orientation, leading to an encouraging improvement in aeroelastic performance without any weight penalty. Through these motivations, further investigation is carried out to investigate the impact of all possible combination of ribs orientation on flutter solution with consideration in sweep angles are taken in account.

\section{Research Methodology}

In this work, the un-tapered wing box models are designed based on previous study of rectangular wing box configuration [24] but with a consideration of sweep angles, $\Lambda$ of $17.5^{\circ}$ and $35^{\circ}$ including $0^{\circ}$. The baseline wing box models consist of leading and trailing spars, with 10 ribs that are evenly distributed along the spanwise direction and they are perpendicular to both spars. Figure 1 shows the planform view of the baseline wing box configurations for the three considered sweep angles. They have similar chord and rib spacing of $70 \mathrm{~mm}$, height of $5 \mathrm{~mm}$, spar thickness of $1 \mathrm{~mm}$ and spar length of $630 \mathrm{~mm}$. Note that a fully constrained boundary condition is defined at the root of the wing and the weight for the three baseline wing models are equal in magnitude. Figure 2 illustrates a sample of planform dimensioning for baseline wing configuration of $35^{\circ}$ in sweep angle. a) $\Lambda=0^{\circ}$

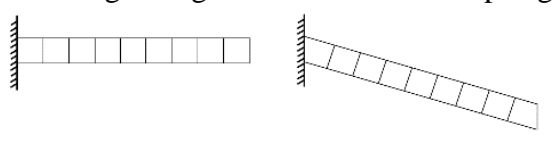

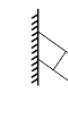

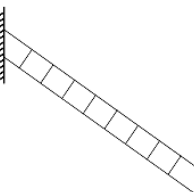

c) $\Lambda=35^{\circ}$
Fig. 1: Planform view of baseline wing box models

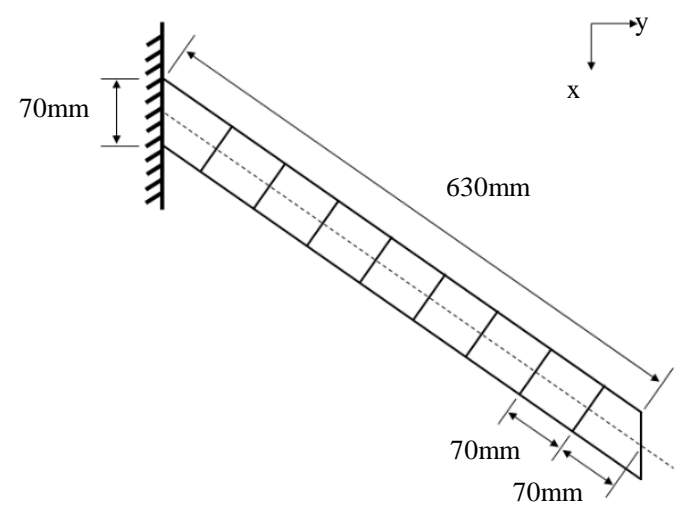

Fig. 2: Planform view of baseline wing model with $35^{\circ}$ sweep angle

Figure 3 shows the finite element (FE) representation of the structural model of wing box that is coupled with aerodynamic panel of doublet lattice method (DLM) for establishing a complete system of aeroelastic model. The FE model of the wing box are defined by the MSC NASTRAN four-node quadrilateral shell elements of CQUAD4 entry with material properties entry of spring steel.

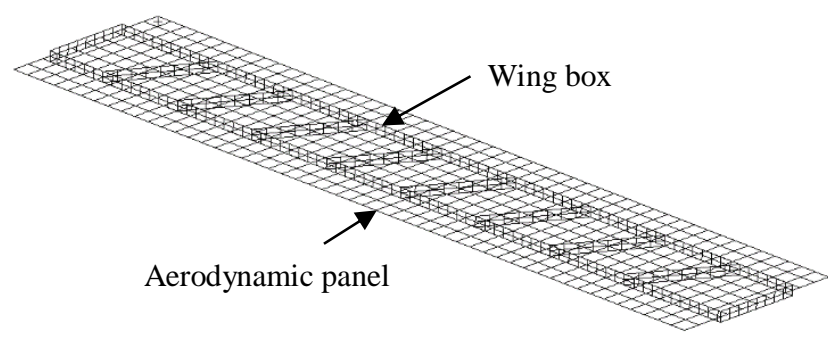

Fig. 3: Aeroelastic wing model

In this work, the considered parametric study is employing a similar procedure as in reference [24]. It should be noted that only the ribs that are located between the root and the tip of the wing are being taken into account for the varying orientations. The considered ribs are numbered accordingly from the root to the tip in increasing order from 1 to 8 with the centre of rotation is defined at the middle of the rib. This allows each rib to be orientated by eight different degrees of rotation from its baseline position with the constraint that they do not overlap each other. In addition, as the rib is orientated, its thickness is adjusted accordingly based to the changes in its length in order to maintain the weight of the model to be equal in all cases. Figure 4 and Table 1 present the schematic of possible rib's orientation as explained in this paragraph. Note that, the negative angle of orientation represents the anticlockwise rotation while the positive angle of orientation refers to clockwise rotation. All solutions involved in this parametric study are coded in MATLAB and the system is integrated with MSC NASTRAN solver under solution 145 of the p-k method flutter analysis [25]. The flutter instability is taken as a criterion to determine the best combinations of ribs orientations. Whereas the divergence instability is not taken into account since in all the cases it occurs later than flutter, thus making flutter instability as a maximum limit among the aeroelastic instabilities. 
$\begin{array}{lllllllll}8 & 7 & 6 & 5 & 0 & 1 & 2 & 3 & 4\end{array}$

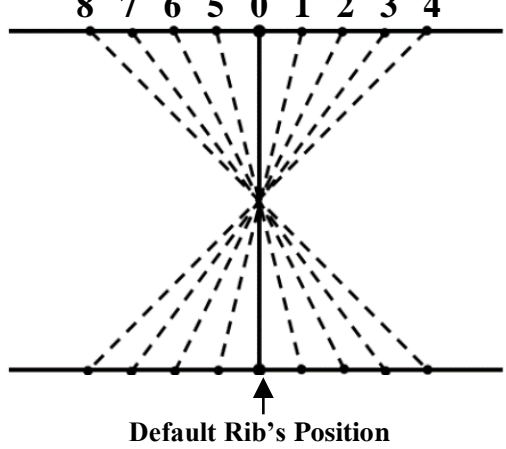

Fig. 4: Possible rib's orientation

Table 1: Rib's angle of orientation and thickness

\begin{tabular}{|c|c|c|c|c|c|c|}
\hline Sweep & \multicolumn{2}{|c|}{$\mathbf{0}^{\circ}$} & \multicolumn{2}{|c|}{$17.5^{\circ}$} & \multicolumn{2}{|c|}{$35^{\circ}$} \\
\hline $\begin{array}{c}\text { Posi- } \\
\text { tion }\end{array}$ & $\begin{array}{l}\text { An- } \\
\text { gle } \\
\left({ }^{\circ}\right)\end{array}$ & $\begin{array}{l}\text { Thick- } \\
\text { ness } \\
(\mathrm{mm})\end{array}$ & $\begin{array}{l}\text { An- } \\
\text { gle } \\
\left({ }^{\circ}\right)\end{array}$ & $\begin{array}{c}\text { Thick- } \\
\text { ness } \\
\text { (mm) }\end{array}$ & $\begin{array}{l}\text { An- } \\
\text { gle } \\
\left({ }^{\circ}\right)\end{array}$ & $\begin{array}{c}\text { Thick- } \\
\text { ness } \\
(\mathrm{mm})\end{array}$ \\
\hline 0 & 0.00 & 0.5000 & 0.00 & 0.5243 & 0.00 & 0.6104 \\
\hline 1 & 14.04 & 0.4851 & 14.69 & 0.5071 & 16.97 & 0.5838 \\
\hline 2 & 26.57 & 0.4472 & 27.67 & 0.4643 & 31.40 & 0.5210 \\
\hline 3 & 36.87 & 0.4000 & 38.18 & 0.4121 & 42.48 & 0.4502 \\
\hline 4 & 45.00 & 0.3536 & 46.36 & 0.3618 & 50.68 & 0.3868 \\
\hline 5 & $\begin{array}{c}- \\
14.04\end{array}$ & 0.4851 & $\begin{array}{c}- \\
14.69\end{array}$ & 0.5071 & $\begin{array}{c}- \\
16.97\end{array}$ & 0.5838 \\
\hline 6 & $\begin{array}{c}- \\
26.57 \\
\end{array}$ & 0.4472 & $\begin{array}{c}- \\
27.67 \\
\end{array}$ & 0.4643 & $\begin{array}{c}- \\
31.40 \\
\end{array}$ & 0.5210 \\
\hline 7 & $\begin{array}{c}- \\
36.87 \\
\end{array}$ & 0.4000 & $\begin{array}{c}- \\
38.18\end{array}$ & 0.4121 & $\begin{array}{c}- \\
42.48 \\
\end{array}$ & 0.4502 \\
\hline 8 & $\begin{array}{c}- \\
45.00\end{array}$ & 0.3536 & $\begin{array}{c}- \\
46.36\end{array}$ & 0.3618 & $\begin{array}{c}- \\
50.68\end{array}$ & 0.3868 \\
\hline
\end{tabular}

\section{Results and discussion}

A series of flutter analysis of $\mathrm{p}-\mathrm{k}$ method has been conducted to assess the bending-torsional characteristics with respect to aeroelastic performance [25]. The flutter analysis is represented in terms of frequency and damping trends over a range of velocities and they are portrayed in terms of $V-f$ and $V-\zeta$ plots respectively. The flutter speed and its corresponding frequency are identified at the condition where the damping ratio changes in sign, which implies that the oscillation cannot be damped out at this particular state.

Figure 5 presents a sample of $V-f$ and $V-\zeta$ plots for the baseline model with $35^{\circ}$ in sweep angle. The flutter speed is identified when the damping trend of the $1^{\text {st }}$ torsional mode changes in sign at an air speed of $19.4 \mathrm{~m} / \mathrm{s}$ with its corresponding flutter frequency of $18.7 \mathrm{~Hz}$. Further to this, it can be seen the $1^{\text {st }}$ bending mode converts into a non-oscillatory solution at an air speed of $18 \mathrm{~m} / \mathrm{s}$ with its damping trend changes in sign at an airspeed of $25 \mathrm{~m} / \mathrm{s}$. This indicates that the divergence instability occurs at this condition, hence showing that the flutter occurs before the divergence which conventionally accepted in terms of wing design aspect.

\subsection{Aeroelastic analysis of individual and parallel ribs orientation}

The first case considers two parametric study of varying individual rib and parallel ribs orientation. Since each of the eight ribs is allowed to rotate into eight different angles excluding its baseline orientation, hence this will lead into a total of 64 possible tailored configurations, while the parallel oriented rib configuration will only lead to a total of 8 possible tailored configurations. Figure 6 presents the flutter speed solution for both individual and parallel oriented rib cases for the two considered sweep angles. In most of the cases, it can be observed that the flutter results are improved as the ribs are oriented from its baseline position except for parallel oriented rib case which shows degradation in flutter speed as the ribs are oriented in the negative angle's orientation.

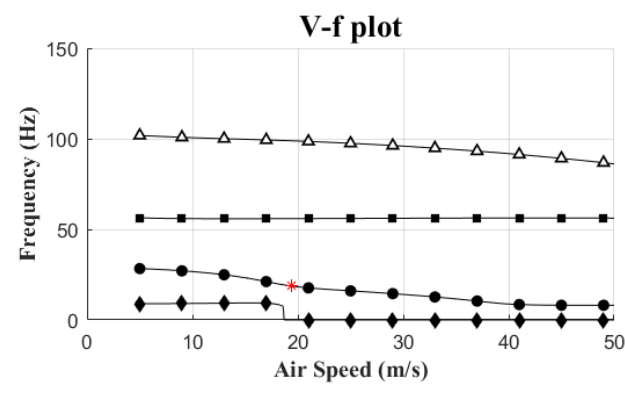

V- $\zeta$ plot

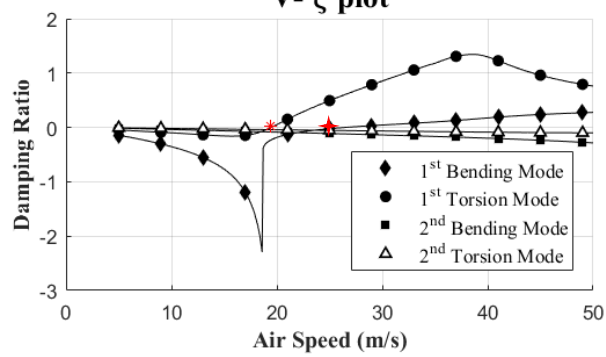

Fig. 5: V-f and V- $\zeta$ plots of selected baseline wing model

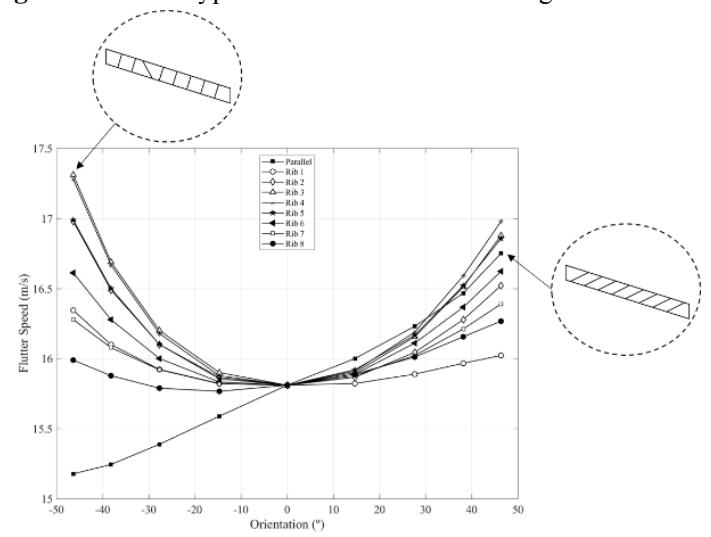

(a) $\Lambda=17.5^{\circ}$

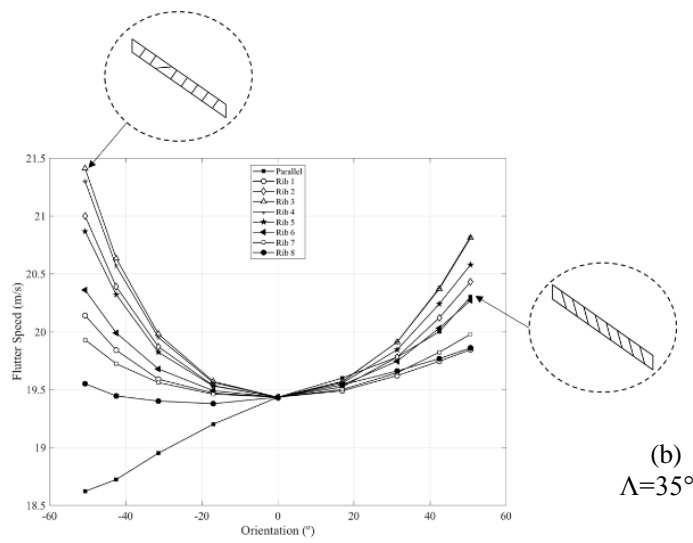

Fig. 6: Flutter speeds for varying individual rib and parallel ribs orientations

Overall, the varying ribs orientation offers improvement in flutter speed when compared to the baseline configuration. For both considered swept wing model, the highest improvement in flutter speed is obtained by rotating the $3^{\text {rd }}$ rib to a maximum negative orientation with an improvement can be seen around 10\% when compared to its corresponding baseline wing configurations. The overall trends of the results for swept back cases are found to be similar with an un-swept wing case as reported in reference [24]. Hence, at this stage, one can assume that similar optimal configu- 
ration is expected for these swept back cases, which will be further described in the next following section. In addition, the finding is aligned with the previous study [22] where the ribs located at the centre part of the wing provide the highest impact to the aeroelastic performance. Apart from that, the finding is also in agreement with $[22,24]$ where the greatest flutter improvement occurs at the largest possible orientation of the rib.

\subsection{Optimal design of wing ribs orientation}

The second case considers the parametric study for all possible combinations of ribs orientation in order to identify the optimal ribs orientation for the swept back cases. Since each of the ribs is allowed to rotate in nine different orientations, this would result in a total of $9^{8}$ possible solutions of tailored ribs orientation. This would be extremely challenging and lengthy if the whole design space is to be solved. Therefore, the parametric range is further simplified by considering only the baseline rib position and the two furthest rib orientation of clockwise and anticlockwise direction, which denotes at position 0,4 and 8 , respectively, of previous Figure 4. These positions are selected based upon the finding that shows the greatest improvement occurs at the furthest angle of orientation from the baseline configuration. Hence, the total possible solutions are now reduced to $3^{8}$ solutions.

Table 2 presents the best five designs for three considered sweep angles while Figures 7, 8, and 9 provide their corresponding planform views. Note that from the results, the flutter speed increases as the sweep angle increases, which is mainly due to the variation in bending-torsional stiffness coupling as sweep angle increases [26]. Remarkable flutter improvement up to $90 \%, 85 \%$ and $79 \%$ for sweep angle of $0^{\circ}, 17.5^{\circ}$ and $35^{\circ}$, respectively, is found when compared to their baseline configuration. Interestingly, it can be observed that the optimum ribs arrangement with an outstanding improvement in flutter speed is more or less in a similar pattern, either in fully zigzag or partly zigzag ribs configuration.

Figure 10,11 and 12 present the $V-f$ and $V-\zeta$ plots for the flutter modes of $1^{\text {st }}$ bending mode and $1^{\text {st }}$ torsional mode between the best configurations and their respective baseline configurations. Note that, the flutter conditions are marked in red star symbol. It is found that the influence of torsional mode to the varying ribs orientation is more significant while the impact to the bending mode is insignificant. This leads to the change in bending-torsional coupling characteristics, resulting to a significant impact in aeroelastic performance.

Further investigation on the figures, it can be seen that the frequency gap for the best configurations are greater in comparison to their baseline configurations. This again justifies that the flutter is primarily affected by the bending-torsional coupling, where the greater frequency gap between the flutter modes will give positive impact to the flutter speed. Therefore, this remarkable outcome might serve as another solution for weight reduction of wing via the oriented rib concept without having to compromise its aeroelastic performance.

Table 2: Flutter speed of the best 5 configurations for each of the considered wing models

\begin{tabular}{|c|c|c|c|}
\hline & \multicolumn{3}{|c|}{ Flutter Speed (m/s) } \\
\hline Sweep Angle & $\mathbf{0}^{\circ}$ & $\mathbf{1 7 . 5}^{\circ}$ & $\mathbf{3 5}^{\circ}$ \\
\hline Configuration 1 & 28.50 & 29.38 & 34.93 \\
\hline Configuration 2 & 28.44 & 29.31 & 34.78 \\
\hline Configuration 3 & 28.44 & 29.29 & 34.61 \\
\hline Configuration 4 & 28.20 & 29.05 & 34.59 \\
\hline Configuration 5 & 28.10 & 29.00 & 34.43 \\
\hline Baseline & 14.99 & 15.81 & 19.43 \\
\hline Best Individual & 16.35 & 17.31 & 21.41 \\
\hline Best Parallel & 15.93 & 17.34 & 20.30 \\
\hline
\end{tabular}

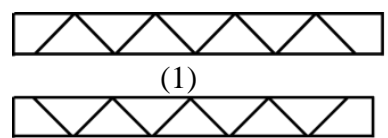

(3)

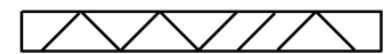

(5)

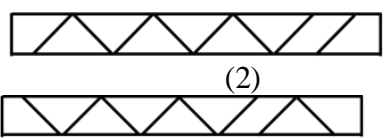

(4)
Fig. 7: Planform view of the best five configurations for wing model of $0^{\circ}$ sweep angle

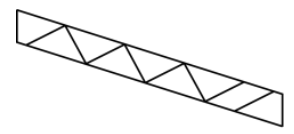

(1)

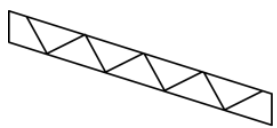

(2)

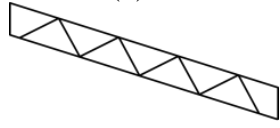

(3)

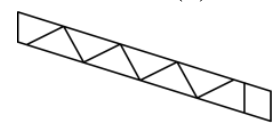

(4)

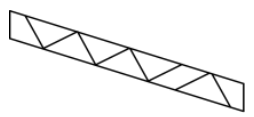

(5)

Fig. 8: Planform view of the best five configurations for wing model of $17.5^{\circ}$ sweep angle

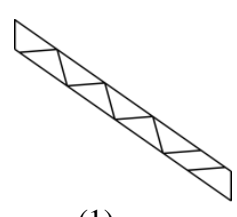

(1)

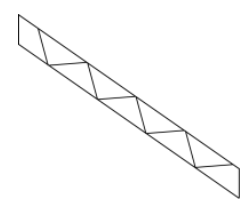

(4)

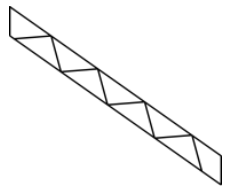

(2)

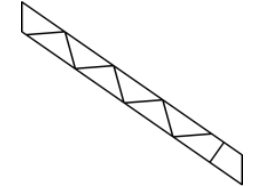

(3)

Fig. 9: Planform view of the best five configurations for wing model of $35^{\circ}$ sweep angle

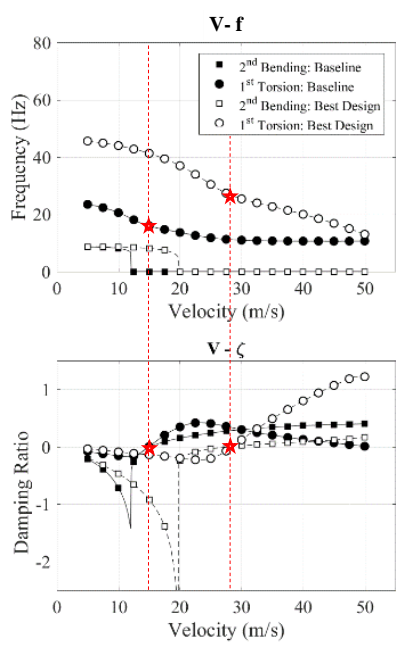

Fig. 10: V-f and V- $\zeta$ plots of best configuration and baseline wing model with $0^{\circ}$ sweep angle

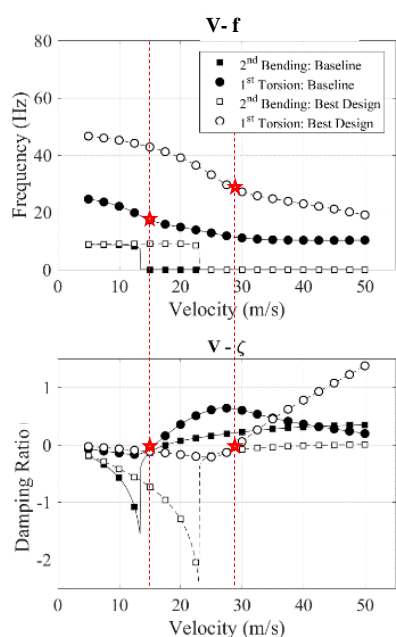

Fig. 11: V-f and V- $\zeta$ plots of best configuration and baseline wing model with $17.5^{\circ}$ sweep angle 


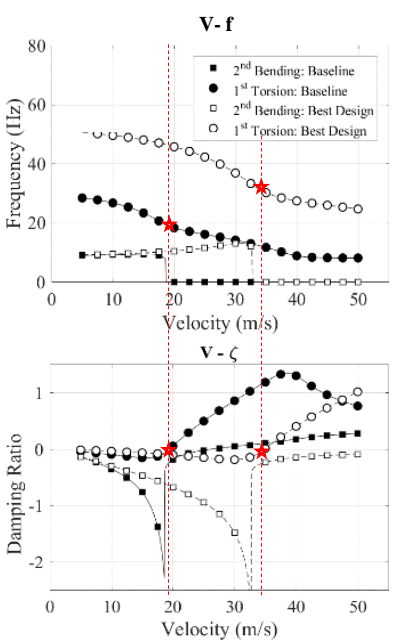

Fig. 12: V-f and V- $\zeta$ plots of best configuration and baseline wing model with $35^{\circ}$ sweep angle

\section{Conclusion}

This study suggests that varying ribs orientation shows significant improvement, not only for unswept wing but for swept back wing as well, with range of improvement from $80-90 \%$ has been found in terms of flutter speed. The optimum configuration for each case is found to have almost similar ribs arrangement with either fully zigzag or partly zigzag configuration. Further research should be undertaken to validate the findings through experimental modal analysis and wind tunnel testing.

\section{Acknowledgement}

The authors acknowledge the support from Universiti Putra Malaysia (UPM) through research grant GP-IPM-9401100 and Ministry of Higher Education (MOHE) through FRGS grant 03-01-15$1625 \mathrm{FR}$

\section{References}

[1] Wright JR \& Cooper JE (2007), Introduction to aircraft aeroelasticity and loads. Wiley.

[2] Hawk J (2005), The Boeing 787-Dreamliner: More than an airplane. Boeing Company.

[3] Narayanaswamy V, Raja LL \& Clemens NT (2012), Control of unsteadiness of a shock wave/turbulent boundary layer interaction by using a pulsed-plasma-jet actuator. Physics of Fluids 24(7), 076101.

[4] Belinger A, Naude N, Cambronne JP \& Caruana D (2014), Plasma synthetic jet actuator: electrical and optical analysis of the discharge. Journal of Physics D: Applied Physics 47(34), 345202.

[5] Jones G, Santer M, Debiasi M \& Papadakis G (2018), Control of flow separation around an airfoil at low Reynolds numbers using periodic surface morphing. Journal of Fluids and Structures 76, 536-557.

[6] Young TM \& Hirst M (2012), Innovation in Aeronautics, Oxford.

[7] Di Luca M, Mintchev S, Heitz G, Noca F \& Floreano D (2017), Bioinspired morphing wings for extended flight envelope and roll control of small drones. Interface Focus 7(1), 20160092.

[8] Kameyama M \& Fukunaga H (2007), Optimum design of composite plate wings for aeroelastic characteristics using lamination parameters. Comput Struct 85(3-4), 213-224.

[9] Guo S (2007), Aeroelastic optimization of an aerobatic aircraft wing structure. Aerosp Sci Technol 11(5), 396-404.

[10] Weisshaar TA \& Duke DK (2006), Induced drag reduction using aeroelastic tailoring with adaptive control surfaces. $J$ Aircraft 43(1), $157-164$.

[11] Georghiades GA, Guo SJ \& Banerjee JR (1996), Flutter characteristics of laminated composite wings. J Aircraft 33(6), 1204-1206.

[12] Guo SJ, Bannerjee JR \& Cheung CW (2003), The effect of laminate lay-up on the flutter speed of composite wings. Proc Inst Mech Eng Part G: J Aerosp Eng 217(G3), 115-22.
[13] Kim TU \& Hwang IH (2005), Optimal design of composite wing subjected to gust loads. Comput Struct 83(19-20), 1546-1554.

[14] Guo SJ, Banerjee JR \& Cheung CW (2003), The effects of laminate lay-up on the flutter speed of composite wings. Journal of Aerospace Engineering 217, 115-122.

[15] Dillinger JKS, Klimmek T, Abdalla MM \& Gürdal Z (2013), Stiffness optimization of composite wings with aeroelastic constraints. $J$ Aircraft 50(4), 1159-68.

[16] Tian W, Yang Z, Gu Y \& Ouyang Y (2016), Aeroelastic tailoring of a composite forward-swept wing using a novel hybrid pattern search method. Journal of Aerospace Engineering 29(6), 04016056.

[17] Locatelli D, Mulani SB \& Kapania RK (2011), Wing-box weight optimization using curvilinear spars and ribs (SpaRibs). Journal of Aircraft 48(5), 1671-1684.

[18] Jutte CV, Stanford BK, Wieseman CD \& Moore JB (2014), Aeroelastic tailoring of the NASA common research model via novel material and structural configurations. 52nd Aerospace Sciences Meeting, AIAA SciTech Forum.

[19] Francois G, Cooper JE \& Weaver PM (2017), Aeroelastic tailoring using the spars and stringers planform geometry. 58th AIAA/ASCE /AHS/ASC Structures, Structural Dynamics, and Materials Conference, AIAA SciTech Forum.

[20] Harmin MY, Ahmed AT \& Cooper JE (2011), Aeroelastic tailoring of metallic wing structures. 52nd AIAA/ASME/ASCE/AHS/ASC Structures, Structural Dynamics and Materials Conference.

[21] Othman MS, Chun OT, Harmin MY \& Romli FI (2016), Aeroelastic effects of a simple rectangular wing-box model with varying rib orientations. IOP Conference Series: Materials Science and Engineering 152(1), 012009.

[22] Chan YN, Harmin MY \& Rafie ASM (2017), Aeroelastic tailoring via ribs orientation of NASA Common Research Model. IOP Conference Series: Materials Science and Engineering 270(1), 012029.

[23] Francios G, Cooper JE \& Weaver PM (2016), Impact of the wing sweep angle and rib orientation on wing structural response for untapered wings. 57th AIAA/ASCE/AHS/ASC Structures, Structural Dynamics, and Materials Conference.

[24] Harmin MY, Othman MS \& Romli FI (2018), Parametric study on the flutter characteristics of a simple rectangular wing-box model with varying ribs orientation. International Journal of Pure and Applied Mathematics 119(15), 3771-3777.

[25] Rodden W \& Johnson E (1994), MSC/NASTRAN Aeroelastic Analysis User's Guide. The Macneal-Schwendler Corporation.

[26] Lottati I (1985), Flutter and divergence aeroelastic characteristics for composite forward swept cantilevered wing. Journal of Aircraft 22(11), 1001-1007. 